\title{
Analisis Kandungan Fitokimia dan Uji Aktivitas Antioksidan dari Tanaman Lire (Hemigraphis repanda (L) Hall F.)
}

\author{
Dina E. B. Rompas ${ }^{{ }^{*}}$, Max. R. J. Runtuwene a, Harry. S. J. Koleangan a \\ aJurusan Kimia, FMIPA, Unsrat, Manado
}

KATA K U N C I

tanaman lire

fitokimia

antioksidan

$\mathrm{IC}_{50}$

\begin{abstract}
A B S T R A K
Telah dilakukan penelitian mengenai analisis kandungan fitokimia dan aktivitas antioksidan dari ekstrak tanaman lire yang diekstraksi secara maserasi dengan menggunakan pelarut etanol. Analisis total kandungan fitokimia yaitu uji fenolik dengan menggunakan metode Folin-Ciocalteu dan uji flavonoid menggunakan metode $\mathrm{AlCl}_{3}$. Uji antioksidan menggunakan metode DPPH. Berdasarkan hasil pengujian kandungan fenolik dan flavonoid ekstrak etanol tanaman lire, menunjukkan bahwa kandungan fenolik lebih tinggi dibandingkan dengan kandungan flavonoid. Hasil pengujian aktivitas antioksidan menunjukkan nilai $I_{50}$ sebesar $108,673 \mathrm{mg} / \mathrm{L}$ pada ekstrak etanol tanaman lire.

A B S T R A C T

Research have been done to analyze the phytochemical compound and antioxidant activity from lire plant extract which was extracted based on maceration method using the ethanol solvent. The phythochemical compound analysing to determining phenolik using Folin-Ciocalteu method and $\mathrm{AlCl}_{3}$ method for flavonoid test. Antioxidant activity using the DPPH method. Based on the result, the phenolic and flavonoid compound from extract ethanol of lire plants, was showed that phenolic compound more higher than flavonoid compound. The result of this test was showed the value of $\mathrm{IC}_{50}$ is $108.673 \mathrm{mg} / \mathrm{L}$ from the lire plant extract.
\end{abstract}

KE Y W O R D S

plant lire

phytochemicals

antioxidants

$\mathrm{IC}_{50}$.

TERSEDIA ONLINE

09 Februari 2016

\section{Pendahuluan \\ Tanaman merupakan salah satu sumber berbagai jenis senyawa-senyawa kimia yang memiliki khasiat sebagai obat. Kandungan senyawa kimia yang ada dalam tanaman disebut dengan fitokimia (Pradhan et al., 2013). Untuk mengetahui kandungan senyawa kimia dalam tanaman dilakukan analisis fitokimia.}

Menurut Prakash (2001), senyawa kimia memiliki banyak kegunaan, salah satunya yaitu dapat dijadikan sebagai sumber antioksidan alami. Antioksidan merupakan suatu senyawa penangkal radikal bebas. Didalam tubuh, ketika terdapat senyawa radikal maka akan menyebabkan suatu penyakit, hal ini karena senyawa radikal dapat merusak sel yang ada dalam tubuh, penyakit yang disebabkan oleh adanya senyawa radikal misalnya penyakit liver dan kanker yang merupakan penyakit yang sulit untuk disembuhkan (Hernani dan Raharjo, 2006).

Tanaman lire (Hemigraphis repanda (L) HallF.) merupakan salah satu jenis tanaman yang dapat dijadikan sebagai tanaman obat yang memiliki manfaat untuk memperlancar/ meluruhkan air seni dan untuk mengobati sariawan (Lingkubi et al., 2012). Menurut Runtuwene dan Pelealu (2014), tanaman lire ini juga memiliki manfaat lain yang dimanfaatkan oleh masyarakat di Provinsi Sulawesi Utara untuk mengobati penyakit kronis seperti penyakit kanker payudara. Kemampuan tanaman lire dalam mengobati penyakit kronis seperti kanker

*Corresponding author: Jurusan Kimia FMIPA UNSRAT, Jl. Kampus Unsrat, Manado, Indonesia 95115; Email address: stevinadinarompas09@gmail.com Published by FMIPA UNSRAT (2016) 
payudara tersebut diduga berkaitan erat dengan fitokimia antioksidan dalam tanaman lire.

Namun kandungan kimia yang ada pada tanaman lire belum banyak diketahui sehingga diperlukan penelitian untuk menganalisis kandungan fitokimia dan aktivitas antioksidan dari tanaman lire yang memiliki manfaat untuk kesehatan di kehidupan masyarakat.

\section{Material dan Metode}

Bahan yang digunakan dalam penelitian ini yaitu tanaman lire yang diperoleh dari desa Boyong Pante Kabupaten Minahasa Selatan, etanol, aluminium klorida 2\%, reagen Folin-Ciocalteu, natrium karbonat 2\%, 1,1-Diphenyl-2-picrylhidrazyl (DPPH), asam klorida pekat, asam galat, petroliumbenzen.

Alat yang digunakan dalam penelitian ini yaitu: alat-alat gelas laboratorium, rak tabung reaksi, blender, timbangan analitik, aluminium foil, kertas saring, spektrofotometer UV-Vis, evaporator, vortex, desikator, ayakan 65 mesh, oven, mikropipet, cawan petri.

\subsection{Pengambilan Sampel dan Preparasi Sampel}

Tanaman lire yang diambil, dicuci, dipotong kecil-kecil dan dikeringanginkan. Setelah dikeringanginkan, sampel kemudian dimasukkan kedalam oven dengan suhu $40^{\circ} \mathrm{C}$ hingga sampel benar-benar kering, lalu diblender, dan diayak dengan ayakan 65 mesh sehingga menjadi serbuk.

\subsection{Penentuan Kadar Air (Sudarmadjiet al., 1989)}

Pengujian kadar air sampel tanaman lire dilakukan mengikuti Sudarmadji (1989), yang dimodifikasi. Ditimbang wadah kosong (W1) yang merupakan tempat untuk sampel. Setelah itu ditimbang sampel sebanyak 2 g (W2), lalu sampel yang ada dalam wadah dimasukkan kedalam oven selama 3 jam dengan suhu $110^{\circ} \mathrm{C}$. Setelah itu, sampel dipindahkan kedalam desikator selama 1 jam lalu ditimbang berat sampel yang ada dalam wadah(W3). Pengujian kadar air dapat dihitung dengan persamaan:

$$
\% \text { Kadar Air }=\frac{(W 1+W 2)-W 3}{W 2} \times 100 \%
$$

\subsection{Ekstraksi}

Ekstraksi sampel dilakukan dengan mengikuti prosedur yang diterapkan Muaja et al. (2013). Serbuk lire dimasukkan kedalam wadah.Kemudian ditambahkan dengan Petroliumbenzen, didiamkan selama 24 jam. Kemudian disaring dan dipisahkan filtrat dan endapan. Endapan yang didapati dimaserasi dengan etanol selama 24 jam. Sampel disaring dan filtrat yang diperoleh ditampung. Sementara itu, endapan hasil penyaringan diekstraksi lagi sebanyak 2 kali seperti cara sebelumnya dengan menggunakan etanol. Filtrat yang diperoleh dievaporasi dengan menggunakan vacum rotary evaporator pada suhu $40^{\circ} \mathrm{C}$ hingga diperoleh ekstrak pekat.

\subsection{Uji Total Kandungan Flavonoid}

Prosedur penentuan kandungan flavonoid menggunakan metode Meda et al. (2005). Dibuat larutan stok dengan konsentrasi sebesar 1000 $\mathrm{mg} / \mathrm{L}$ dari sampel ekstrak etanol tanaman lire, lalu diencerkan menjadi $100 \mathrm{mg} / \mathrm{L}$ yang akan digunakan sebagai larutan uji. Sebanyak $1 \mathrm{~mL}$ Iarutan uji ditambahkan dengan $2 \mathrm{~mL}$ aluminium klorida $2 \%$ yang telah dilarutkan dalam etanol. Absorbansi ekstrak dibaca pada spektrofotometer UV-Vis pada ᄉ $415 \mathrm{~nm}$. Kandungan total flavonoid dinyatakan sebagai ekuivalen kuersetin dalam $\mathrm{mg} / \mathrm{kg}$ ekstrak.

\subsection{Uji Kandungan Total Fenolik}

Kandungan total fenolik dalam ekstrak etanol tanaman lire ditentukan dengan metode Jeong et al. (2005) yang dimodifikasi. Dibuat larutan stok dengan konsentrasi larutan sampel ekstrak sebesar $1000 \mathrm{mg} / \mathrm{L}$, dan diencerkan menjadi $100 \mathrm{mg} / \mathrm{L}$ sebagi larutan uji. Sebanyak 0,1 mL Iarutan uji ditambahkan dengan 0,1 $\mathrm{mL}$ folin-ciociltau. Setelah itu, ditambahkan dengan $2 \mathrm{~mL}$ larutan $\mathrm{NaCO}_{3} 2 \%$. Kemudian diinkubasi dan absorbansinya dibaca dengan spektrofotometer UV-Vis pada $\lambda 750 \mathrm{~nm}$. Hasil yang didapat, dinyatakan sebagai ekuivalen asam galat dalam $\mathrm{mg} / \mathrm{L}$ ekstrak.

\subsection{Penentuan Aktivitas Antioksidan dengan metode DPPH (Burda dan Oleszek, 2001)}

Pengujian aktivitas antioksidan ini dibuat larutan uji dengan konsentrasi 50, 100, 150, 200, $250 \mathrm{mg} / \mathrm{L}$. Sebanyak 0,5 mL masing- masing larutan uji ditambahkan dengan $1 \mathrm{~mL}$ larutan 1,1difenil-2-pikrilhidrazil (DPPH) dalam etanol. Setelah itu, diinkubasi selama 30 menit kemudian absorbansi diukur pada panjang gelombang $517 \mathrm{~nm}$ dengan menggunakan spektrofotometer UV-Vis. Aktivitas penangkal radikal bebas dihitung dengan menggunakan rumus:

Aktifitas penangkal radikal bebas (\%)=

$$
1-\frac{\text { absorbansi sampel }}{\text { absorbansi kontrol }} x 100 \%
$$

\section{Hasil dan Pembahasan}

\subsection{Kadar Air Tanaman Lire (Hemigraphis repanda} (L) Hall. F)

Pada pengujian kadar air dilakukan 2 kali pengulangan sampai nilai kadar air konstan. Kadar air dalam penelitian ini dapat dilihat pada tabel 1.

Tabel 1. Kadar Air sampel Tanaman Lire

\begin{tabular}{ll}
\hline Pengujian Sampel & Kadar Air (\%) \\
\hline Ulangan I & 5,089 \\
Ulangan II & 5,089 \\
\hline
\end{tabular}

Berdasarkan tabel 1, kadar air pada ulangan I dan ulangan II memiliki nilai yang sama. Hal ini 
berarti kadar air tanaman lire sudah konstan dan hasil yang diperoleh, rata-rata kadar air tanaman lire adalah 5,203\%. Kadar air pada sampel tanaman lire ini telah memenuhi syarat untuk kadar air yang ditetapkan yaitu kadar air yang dibawah batas maksimum $10 \%$, hal ini bertujuan agar supaya selsel mikroorganisme yang masih terdapat dalam kadar air yang tinggi menjadi lebih kecil, sehingga akan mempengaruhi senyawa-senyawa kimia yang ada dalam sampel.

\subsection{Ekstraksi}

Ekstraksi dilakukan dengan metode maserasi yang merupakan salah satu metode yang digunakan untuk ekstraksi. Selain itu juga metode maserasi merupakan metode yang paling praktis dalam ekstraksi. Sampel yang diekstraksi dengan etanol selama 3x24 jam menghasilkan ekstrak sebanyak 0,7816 g. Dari ekstrak yang didapat, dihitung jumlah persen rendemen, dan diperoleh hasil rendemen sebanyak 1,5632 \%. Hal ini karena senyawa yang ada dalam ekstrak tanaman lire mudah tereksitasi dengan pelarut etanol. Suatu rendemen ekstrak yang terekstraksi dapat ditunjukkan adanya efektivitas pelarut yang digunakan, sehingga ketika rendemen ekstrak tinggi maka semakin banyak komponen yang akan terekstrak.

\subsection{Kandungan Total Fenolik dan Flavonoid}

Hasil uji kandungan total fenolik dan flavonoid ekstrak tanaman lire dapat dilihat pada Gambar 1 :

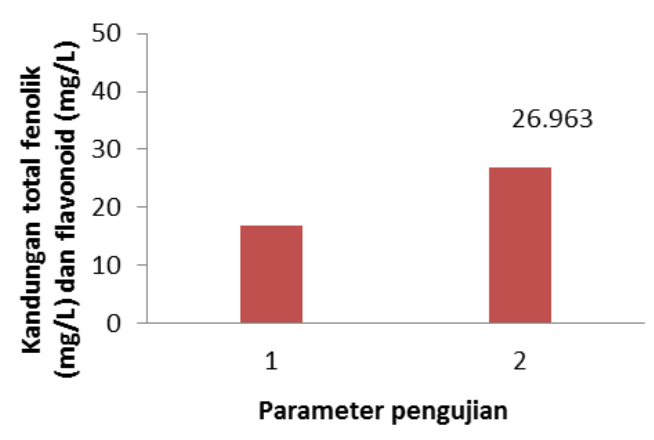

Gambar 1. Kandungan total fenolik dan flavonoid tanaman lire (Hemigraphis rependa Hall F.)

Gambar 1 diatas, menunjukkan bahwa tanaman lire memiliki kandungan fenolik yang lebih tinggi dari kandungan flavonoid. Pengujian kandungan fenolik dan flavonoid dibuat pada konsentrasi $100 \mathrm{mg} / \mathrm{L}$. Pengujian flavonoid untuk larutan sampel tanaman lire dilakukan dengan penambahan $2 \mathrm{~mL} \mathrm{AICl} 32 \%$ pada $1 \mathrm{~mL}$ larutan sampel dan diukur pada panjang gelombang 415 $\mathrm{nm}$. Absorbansi yang terukur dihitung dengan menggunakan kurva standar kuersetin untuk mendapatkan kandungan total flavonoid, sedangkan untuk kandungan fenolik dihitung menggunakan kurva standar asam galat. Hasil kandungan total flavonoid yaitu $26,933 \mathrm{mg} / \mathrm{L}$. Tanaman lire yang diuji kandungan flavonoid baik secara kualitatif maupun kuantitatif menunjukkan bahwa tanaman lire mengandung senyawa flavonoid. Flavonoid merupakan salah satu senyawa fitokimia yang ada didalam jaringan tumbuhan (Rajalakshmi dan Narasimhan, 1985). Flavonoid juga termasuk dalam golongan senyawa fenolik (White dan Xing, 1951).

Hasil pengujian untuk fenolik ketika ditambahkan dengan reagen folin-ciocalteu dan $\mathrm{Na}_{2} \mathrm{CO}_{3}$ mengalami perubahan warna dari kuning menjadi biru dan diukur pada $\lambda 750 \mathrm{~nm}$. Perubahan warna biru pada larutan sampel disebabkan terbentuknya ion fenolat dalam larutan sampel. Ion fenolat hanya terdapat dalam larutan basa, sedangkan reagen folin-ciocalteu dan produk yang dihasilkan tidak stabil pada kondisi basa. Sehingga ketika terbentuknya ion fenolat dalam pengujian fenolik maka warna biru yang dihasilkan semakin pekat (Rossi, 1965). Dan hasil kandungan fenolik yang diperoleh yaitu $33,713 \mathrm{mg} / \mathrm{L}$.

Berdasarkan pengujian kandungan fenolik dan flavonoid baik kualitatif maupun kuantitatif, tanaman lire mengandung senyawa fenolik dan flavonoid. Senyawa flavonoid dan fenolik memiliki peran untuk melindungi dari serangan yang ada disekitar seperti serangan radikal bebas, sehingga senyawa fenolik dan flavonoid berfungsi sebagai antioksidan (Atmoko dan Ma'ruf, 2009). Sehingga dari hasil pengujian kandungan fenolik dan flavonoid dapat disimpulkan banwa tanaman lire berpotensi sebagai penangkal radikal bebas.

\subsection{Aktivitas Antioksidan dengan Metode1,1difenil- 2-pikrilhidrazil (DPPH)}

Pengujian aktivitas antioksidan pada penelitian ini menggunakan metode DPPH. Konsentrasi larutan uji yaitu 50, 100, 150, 200, dan 250 mg/L yang diencerkan dari konsentrasi larutan stok 1000 $\mathrm{mg} / \mathrm{L}$. Pengujian dilakukan dengan cara menambahkan $2 \mathrm{~mL}$ larutan DPPH dalam $1 \mathrm{~mL}$ larutan uji. Reaksi yang terjadi ketika ditambahkan larutan DPPH pada larutan sampel yaitu dengan berubahnya warna dari ungu menjadi kuning. Absorbansi DPPH yang terukur dibaca pada panjang gelombang $517 \mathrm{~nm}$. Intensitas perubahan warna diakibatkan karena adanya pelepasan atom hidrogen dari senyawa fenolik kepada senyawa radikal yang terdapat pada senyawa DPPH. Hasil yang diperoleh dapat ditunjukkan pada Gambar 2.

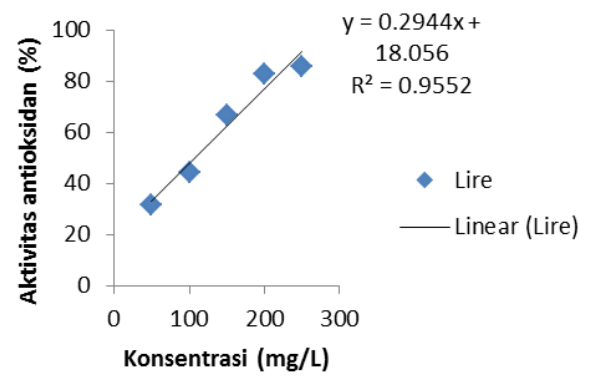

Gambar 2. Aktivitas Antioksidan DPPH 
Berdasarkan Gambar 2, hasil aktivitas antioksidan DPPH yang paling tinggi terdapat pada konsentrasi $250 \mathrm{mg} / \mathrm{L}$ yaitu 85,797 \% dan yang terendah pada konsentrasi $50 \mathrm{mg} / \mathrm{L}$ yaitu 31,561 $\%$. Aktivitas antioksidan DPPH pada tanaman lire berdasarkan hasil yang didapat yakni semakin besar konsentrasi larutan uji semakin tinggi aktivitas antioksidan DPPH yang diperoleh, dan aktivitas antioksidannya rata-rata diatas 50\%. Menurut Lai et al. (2001), ketika terdapat penambahan ekstrak sampai pada konsentrasi tertentu maka aktivitas penangkal radikal bebas DPPH umumnya akan naik, begitu pula sebaliknya aktivitas antioksidan akan turun dengan adanya penambahan konsentrasi yang lebih besar. Selanjutnya melalui persamaan linear yang didapat, dihitung nilai $I_{50}$. Nilai $I_{50}$ yang diperoleh pada ekstrak tanaman lie yaitu $108,673 \mathrm{mg} / \mathrm{L}$. IC50 merupakan konsentrasi larutan sampel yang mampu mereduksi aktivitas DPPH sebesar 50 \%.Semakin rendah nilai $\mathrm{IC}_{50}$, semakin baik aktifitas antioksidannya.

Hal ini dapat disimpulkan bahwa tanaman lire memiliki aktivitas antioksidan yang tinggi, dan mampu menangkal radikal bebas sebesar $50 \%$, karena pada tanaman lire memiliki kandungan fitokimia.

Struktur DPPH dan reaksinya dengan antioksidan ditunjukkan pada Gambar 3.

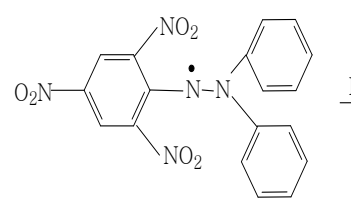

DPPH Radikal (ungu)

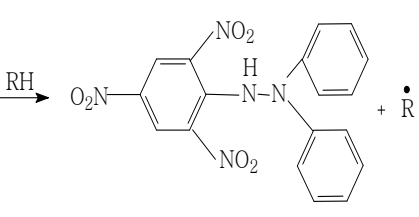

DPPH Stabil (kuning)
Gambar 3. Kandungan total fenolik dan flavonoid tanaman lire (Hemigraphis rependa Hall F.)

\section{Kesimpulan}

Berdasarkan hasil penelitian yang diperoleh, maka dapat disimpulkan bahwa :

1. Ekstrak etanol tanaman lire memiliki kandungan fenolik yang lebih tinggi dibandingkan kandungan flavonoid.

2. Hasil pengujian aktivitas antioksidan dengan menggunakan metode DPPH, aktivitas antioksidan yang paling tinggi terdapat pada konsentrasi $250 \mathrm{mg} / \mathrm{L}$ dan yang terendah pada konsentrasi $50 \mathrm{mg} / \mathrm{L}$. Semakin tinggi konsentrasi larutan sampel, maka semakin tinggi aktivitas antioksidan DPPH pada tanaman lire. Berdasarkan nilai IC50aktivitas antioksidan dari DPPH menunjukkan bahwa tanaman lire memiliki aktivitas antioksidan DPPH yang tinggi yaitu nilai IC50 sebesar108,673 mg/L.

\section{Daftar Pustaka}

Atmoko, T. \& A. Ma'ruf. 2009. Uji Toksisitas dan Skrining Fitokimia Ekstrak Tumbuhan Sumber Pakan Orangutan Terhadap Larva Artemia Salina L. Jurnal Penelitian dan Konservasi Alam.6: 37-45.

Burda S. \& Oleszek W. 2001.Antioxidant and antiradical activities of flavonoids. J.Food Chemistry .49:2774-2779.

Hernani \& Raharjo, 2006.Tanaman berkhasiat sebagai Antioksidan Penebar Swadaya, Jakarta.

Jeong, S.M., S. Y. Kim, D. R. Kim, S. C. Jo, K. C. Nam, D. U. Ahn,\&S. C. Lee. 2005. Effect of Heat Treatment on the Antioxidant Activity of Extracts from Citrus Peels. J. Agric. Food Chem. 33: 213-217.

Lingkubi, J. R., M. Y. M. A. Sumakut, W. Nurmawan, \& E. F. S. Pangemanan.2012.Pemanfaatan Tumbuhan Obat di Kecamatan Bunaken, Kota Manado, Provinsi Sulawesi Utara. Faperta Unsrat:Manado.

Meda, A., C. E. Lamien, Romito \&M. Millogo J., O. G. Nacoulma. 2005. Determination of the total phenolic, flavonoid and proline contents in Burkina Faso honeys as well as their radical scavenging activity. J. Food Chem. 91: 571-577.

Muaja.A D., H. S. J. Koleangan, M. R. J. Runtuwene.2013.Uji Toksisitas dengan Metode BSLT dan Analisis Kandungan Fitokimia Ekstrak Daun Soyogik (Saurauia bracteosa DC) dengan Metode Soxhletasi. J.Mipa Unsrat Online. 2: 115-118.

Pradhan,C., M. Mohanty.,A.Rout., A. B. Das.,K.B.Satupathy,\& H.K.Patra. 2013. Phytocosintituent Screnning and Comparative Assessment of Antimicrobial Potentiality of Artocaprus atilis Fruit Extract. International J. of Pharmacy and Pharmaceutical Sciences. 5: 840-843.

Prakash,A.2001.Antioxidant Activity.Medallion Laboratories: Analytical Progress.19:1-4.

Rajalakshmi, D \& S. Narasimhan. 1985. Food Antioxidants: Sources and Methods of Evaluation dalam D.L. Madhavi: Food Antioxidant, Technological, Toxilogical and Health Perspectives. Marcel Dekker Inc., Hongkong: 76-77.

Runtuwene, M. R. J \& J. Pelealu. 2014. Eksplorasi dan Uji Fitokimia Biodeversitas Tumbuhan Antikanker di Kawasan Pasifik (Provinsi Sulawesi Utara dan Maluku Utara). UNSRAT. Manado.

Sudarmadji, S., B.Haryono,\& Suhardi. 1989. Prosedur Analisis untuk Bahan Makanandan Pertanian. Liberty. Jogjakarta.

White, P.J. \& Y. Xing. 1954. Antioxidants from Cereals and Legumes dalam Foreidoon Shahidi: Natural Antioxidants, Chemistry, Health Effect and Applications. AOCS Press, Champaign, Illinois 9:25-63. 